\title{
Clinical activity at the UK military level 2 hospital near Bentiu, South Sudan during Op TRENTON from June 2017 to October 2018
}

\section{Anonymised}

The clinical activity data collected by Bailey et al. ${ }^{1}$ during Op TRENTON roulements $2 \& 3 \mathrm{~A}$ from 19 Jun 2017 to 24 Sep 2017 proved useful during pre-deployment preparation for subsequent Op TRENTON roulements 3B, 4A, 4B \& 5A from 25 Sep 2017 to 25 Oct 2018. We updated and continued this data collection using the same methods in order to obtain a complete dataset for the whole of the Op TRENTON deployment and to look for trends.

During the whole 16-month deployment period from 19 Jun 2017 to 25 Oct 2018, a total of 596 patients were seen at the UK level 2 hospital including those 'bedded down' by the UK level 1 primary healthcare team. As previously reported, 286 (50\%) of these were admitted during the first 3 months of the deployment ${ }^{1}$ and most of the data reported at that stage was similar in percentage terms to our findings for the whole deployment (Table 1). However, there were some significant differences in the clinical activity between the first 3 months and the remaining 13 months (Table 1 ).

The number of new patients seen reduced from 20 per week to 5 per week and the proportion of UK military patients halved from $50 \%$ to $25 \%$ with a corresponding increase in the proportion of UN staff patients. The admission rate reduced from $52 \%$ to $34 \%$, the length of stay reduced from 2.4 days to 1.8 days and the "return to unit" rate reduced from $98 \%$ to $92 \%$. These figures are probably due to the large number of acute gastroenteritis (AGE) cases that occurred in UK military staff during the first 3 months, because these usually required admission for isolation until their symptoms resolved and were then able to return to their units without any need for medical evacuation. ${ }^{2}$

Despite a marked decrease in AGE cases, the proportion of patients requiring definitive care from medicine specialists (general physicians) remained high (44\% to $47 \%$ ). Most of the remaining patients received definitive care from the emergency medicine team ( $41 \%$ to $31 \%$ ), which highlights their important role in supporting the primary healthcare teams dealing with a range of minor illnesses and injuries.

Throughout this deployment, the number of cases due to "disease" remained high $(79 \%$ to $71 \%$ ) despite reductions in the proportion of cases due to AGE (from $36 \%$ to $6 \%$ ) and undiagnosed non-malarial undifferentiated febrile illness (UNMUFI) ${ }^{3}$ (from $13 \%$ to $6 \%$ ). Further analysis shows that the decrease in AGE cases was most marked after the first roulement-in-place of UK troops had been completed and that it decreased again after a new water borehole and plumbing system were brought online.

Our conclusions are :

1. Clinical activity data at 3 months was representative of the whole deployment in most respects and so was useful for pre-deployment preparation. ${ }^{1}$

2. Disease was responsible for $75 \%$ of all cases seen with no significant variation throughout the deployment. 
3. Medicine specialists (general physicians) provided definitive care for the most patients (46\%) even after AGE and UNMUFI cases declined.

4. AGE outbreaks remain a problem during the initial stages of UK military deployments, but can be brought under control. ${ }^{2}$

Future deployments to similar environments (eg. Mali) are likely to see similar clinical activity and so operational planning should take account of these findings.

References:

1. Bailey MS, Gurney I, Lentaigne J, Biswas JS, Hill NE. Clinical activity at the UK military level 2 hospital in Bentiu, South Sudan during Op TRENTON from June to September 2017. J R Army Med Corps 2019 Apr 20. pii: jramc-2018-001154. doi: 10.1136/jramc-2018-001154. [Epub ahead of print]

2. Biswas JS, Lentaigne J, Hill NE, et al. Epidemiology and etiology of diarrhea in UK military personnel serving on the United Nations Mission in South Sudan in 2017: A prospective cohort study. Travel Med Infect Dis. 2019;28:34-40. doi: 10.1016/j.tmaid.2018.12.004. Epub 2018 Dec 12.

3. Biswas JS, Lentaigne J, Burns DS, et al. Undifferentiated febrile illnesses in South Sudan: a case series from Operation TRENTON from June to August 2017. BMJ Mil Health 2020 Feb 23. pii: jramc-2019-001238. doi: 10.1136/jramc-2019-001238. [Epub ahead of print]. 
Table 1. Patients seen at the UK L2H near Bentiu during Op TRENTON

\begin{tabular}{|c|c|c|c|c|}
\hline & $\begin{array}{l}\text { Total from } \\
\text { Jun } 2017 \text { to } \\
\text { Oct } 2018\end{array}$ & $\begin{array}{l}19 \text { Jun } 2017 \text { to } \\
24 \text { Sep } 2017^{1}\end{array}$ & $\begin{array}{c}25 \text { Sep } 2017 \text { to } \\
25 \text { Oct } 2018\end{array}$ & Difference* \\
\hline Patients & $576(100 \%)$ & $286(50 \%)$ & $290(50 \%)$ & NS \\
\hline Patients per week & 8 & 20 & 5 & $P<0.01$ \\
\hline Males & $483(84 \%)$ & $244(85 \%)$ & $239(82 \%)$ & NS \\
\hline Females & $93(16 \%)$ & $42(15 \%)$ & $51(18 \%)$ & NS \\
\hline Age - range (years) & $15-64$ & $19-56$ & $15-64$ & NS \\
\hline Age - median (years) & 33 & 31 & 35 & $P<0.01$ \\
\hline Age - mean (years, & 34.8 & 33.1 & 36.3 & $P<0.01$ \\
\hline UK military staff & $215(37 \%)$ & $142(50 \%)$ & $73(25 \%)$ & $P<0.01$ \\
\hline UN civilian staff & $212(37 \%)$ & $84(29 \%)$ & $128(44 \%)$ & $P<0.01$ \\
\hline UN military staff & $143(25 \%)$ & $57(21 \%)$ & $83(29 \%)$ & $P=0.03$ \\
\hline Other civilians & $6(1 \%)$ & $0(0 \%)$ & $6(2 \%)$ & $P=0.02$ \\
\hline Admitted & $248(43 \%)$ & $149(52 \%)$ & 99 (34\%) & $P<0.01$ \\
\hline Length of stay - range (days) & $0-7$ & $1-7$ & $0-6$ & NS \\
\hline Length of stay - median (days) & 2 & 2 & 2 & NS \\
\hline Length of stay - mean (days) & $\overline{2} . \overline{1}$ & 2.4 & 1.8 & $P<0.01$ \\
\hline Returned to unit & $545(95 \%)$ & $279(98 \%)$ & $266(92 \%)$ & $P<0.01$ \\
\hline Medically evacuated & $30(5 \%)$ & $7(2 \%)$ & $23(8 \%)$ & $P<0.01$ \\
\hline Died & $1(<1 \%)$ & $0(0 \%)$ & $1(<1 \%)$ & NS \\
\hline Seen first by EM & $362(63 \%)$ & $181(63 \%)$ & $187(62 \%)$ & NS \\
\hline Definitive care by MED & $263(46 \%)$ & $126(44 \%)$ & $137(47 \%)$ & NS \\
\hline Definitive care by EM & $208(36 \%)$ & $118(41 \%)$ & $90(31 \%)$ & $P=0.01$ \\
\hline Definitive care by PHC & $33(6 \%)$ & $27(9 \%)$ & $6(2 \%)$ & $P<0.01$ \\
\hline Definitive care by SURG & $31(5 \%)$ & $4(1 \%)$ & $27(9 \%)$ & $P<0.01$ \\
\hline Definitive care by ORTHO & $28(5 \%)$ & $4(1 \%)$ & $24(8 \%)$ & $P<0.01$ \\
\hline Definitive care by PLASTICS & $7(1 \%)$ & $5(2 \%)$ & $2(1 \%)$ & NS \\
\hline Definitive care by MED + ICM & $6(1 \%)$ & $2(1 \%)$ & $4(1 \%)$ & NS \\
\hline Disease & $430(75 \%)$ & $226(79 \%)$ & $206(71 \%)$ & NS \\
\hline Non-battle injury & $138(24 \%)$ & $60(21 \%)$ & $78(27 \%)$ & NS \\
\hline Battle injury & $6(1 \%)$ & $0(0 \%)$ & $6(2 \%)$ & $P=0.02$ \\
\hline Infection-related & $302(52 \%)$ & $188(66 \%)$ & $114(39 \%)$ & $P<0.01$ \\
\hline AGE & $121(21 \%)$ & $103(36 \%)$ & $18(6 \%)$ & $P<0.01$ \\
\hline UNMUFI & $52(9 \%)$ & $36(13 \%)$ & $16(6 \%)$ & $P<0.01$ \\
\hline Malaria & $33(6 \%)$ & $19(7 \%)$ & $14(5 \%)$ & NS \\
\hline Chemical pneumonitis & $23(4 \%)$ & $23(8 \%)$ & $0(0 \%)$ & $P<0.01$ \\
\hline
\end{tabular}

*Difference between values recorded for Jun - Sep 2017 and Sep 2017 - Oct 2018.

NS, not significant; EM, emergency medicine; MED, general medicine; PHC, primary healthcare; SURG, general surgery; ORTHO, orthopaedic surgery; PLASTICS, plastic surgery; ICM, intensive care medicine; AGE, acute gastroenteritis; UNMUFI, undiagnosed non-malarial undifferentiated febrile illness. 